\title{
Memória fraca e patrimônio queimado
}

\section{Poor memory and burnt heritage}

\section{Memoria débil y patrimonio quemado}

\author{
Rosany Bochner ${ }^{1, a}$ \\ rosany.bochner@icict.fiocruz.br | https://orcid.org/0000-0002-8797-8874
}

\begin{abstract}
${ }^{1}$ Fundação Oswaldo Cruz, Instituto de Comunicação e Informação Científica e Tecnológica em Saúde, Laboratório de Informação Científica e Tecnológica em Saúde. Rio de Janeiro, RJ, Brasil.
\end{abstract}

Doutorado em Saúde Pública pela Fundação Oswaldo Cruz.

Palavras-chave: Memória; Patrimônio público; História; Incêndio; Museu Nacional.

Keywords: Memory; Public heritage; History; Fire; National Museum of Brazil.

Palabras clave: Memoria; Patrimonio público; Historia; Incendio; Museo Nacional de Brasil.

“Aqueles que não conseguem lembrar o passado, estão condenados a repeti-lo” George Santayana, A vida da razão

O recente incêndio do Museu Nacional em 2 de setembro de 2018 queimou mais uma parte da memória do país, deixando a população culturalmente mais pobre e as autoridades sedentas por apontar culpados e transferir suas responsabilidades. Infelizmente, esse evento está muito longe de ser um fato isolado. Desde 2011, quando um incêndio na Praia Vermelha destruiu parte do Palácio Universitário e a capela São Pedro de Alcântara, datada de 1850 e tombada pelo Instituto do Patrimônio Histórico e Artístico Nacional (Iphan)1, a Universidade Federal do Rio de Janeiro (UFRJ) vem sofrendo incêndios em seus prédios. Em 10 de setembro de 2012, foi a vez da Faculdade de Letras, localizada na Cidade Universitária, ser atingida pelo fogo ${ }^{2}$. Em 10 de dezembro de 2014, um curto-circuito em um aparelho de ar-condicionado provocou um incêndio no laboratório de microbiologia do Centro de Ciências da Saúde (CCS), também localizado na Cidade Universitária ${ }^{3}$. Em 3 de outubro de 2016, no mesmo campus, uma sala do $8^{\circ}$ andar do prédio da Pró-Reitoria de Gestão e Governança (PR-6) foi atingida por um incêndio4. Em 2 de agosto de 2017, novamente na Cidade Universitária, o alojamento de estudantes pegou fogo, deixando quatro moradores feridos ${ }^{5}$. Além desses casos, somente em 2018 a mesma instituição já enfrentou em 23 de maio um princípio de incêndio em uma ala desativada do Hospital Universitário Clementino Fraga Filho ${ }^{6,7}$ e em 15 de agosto uma explosão em um laboratório do Instituto Alberto Luiz Coimbra de Pós-Graduação e Pesquisa de Engenharia (Coppe), que deixou três feridos ${ }^{8}$. 
Além da UFRJ, outras instituições, públicas e privadas, localizadas em outros estados do país também tiveram seus acervos destruídos pelo fogo ou, seria melhor dizer, pela falta de recursos destinados à cultura.

Em 2 de março de 1905, a Faculdade de Medicina da Bahia, em Salvador, sofreu um incêndio que destruiu completamente sua biblioteca e algumas de suas dependências, entre elas o Gabinete de Medicina Legal dirigido por Nina Rodrigues. Nesse episódio foram perdidos 22.000 volumes. A biblioteca foi reconstruída com doações de particulares e instituições. Em outubro de 1951, outro prédio da instituição sofreu um incêndio. Em 2005, não foi o fogo que veio destruir a biblioteca, foram o descaso e o abandono que fizeram seu telhado desabar, colocando o mobiliário e boa parte do acervo expostos à ação da chuva. Como é comum acontecer, depois do desastre consumado, providências foram tomadas e um investimento significativo foi destinado à restauração do que ainda poderia ser recuperado9. Cento e treze anos depois do incêndio na Faculdade de Medicina, comportamento similar é observado após o ocorrido no Museu Nacional do Rio de Janeiro.

Em 27 de janeiro de 1957, um incêndio na Cinemateca Brasileira, localizada na cidade de São Paulo, a fez perder quase todo o seu acervo, este composto de clássicos do cinema, os primeiros documentos cinematográficos nacionais, documentários cobrindo um longo período da história do Brasil, além de material estrangeiro proveniente da Alemanha, Rússia, França, Itália, Japão e Estados Unidos ${ }^{10}$. Outros três incêndios foram registrados na cinemateca, em 1969, 1982 e 2016 ${ }^{10,11}$.

Em 1969 o Palácio do Catete, que abriga o Museu da República, localizado no bairro do Catete, na cidade do Rio de Janeiro, pegou fogo a partir de chamas que se alastram do quarto do ex-presidente Getúlio Vargas ${ }^{10}$.

Em 8 de julho de 1978, há 40 anos, no Rio de Janeiro, um grande incêndio destruiu 95\% do acervo do Museu de Arte Moderna (MAM), localizado no Aterro do Flamengo. Foram queimados quadros de artistas como Torres Garcia, Picasso, Van Gogh, Salvador Dali, Di Cavalcanlti, Miró e Cândido Portinari, além dos nove mil volumes da biblioteca do museu ${ }^{10,12}$. A repercussão internacional foi tamanha que somente nos anos de 1990 o país voltou a receber exposições de grande porte, vindas do exterior ${ }^{13}$.

A exposição “Arte Agora III, América Latina: Geometria sensível”, completamente destruída no incêndio de 1978, recebe homenagem na mostra "Construções sensíveis: a experiência geométrica latino-americana na coleção Ella Fontanals - Cisneros", em cartaz no Centro Cultural Banco do Brasil (CCBB), no Rio de Janeiro neste mês de setembro ${ }^{14}$.

Em 1981 ocorreu o incêndio no Museu da Imagem e do Som (MIS) localizado na cidade do Rio de Janeiro. Uma grande falha nos equipamentos de água foi relatada, sendo o último laudo do Corpo de Bombeiros datado de 1979, quando houve o último recarregamento dos extintores de incêndio ${ }^{10}$. Trinta e sete anos depois, problemas similares nos equipamentos de contenção do fogo também foram observados no incêndio do Museu Nacional do Rio de Janeiro ${ }^{15}$.

Em 1982, o MAM do Rio de Janeiro sofreu um novo incêndio, mas ao contrário do ocorrido em 1978, esse foi rapidamente controlado ${ }^{10}$.

Em 17 de maio de 2007, na capital paulista, a queda de um balão no telhado do Centro Cultural São Paulo causou um incêndio, e a água utilizada para controlar o fogo danificou 2.50o documentos históricos e parte de uma exposição ${ }^{10}$.

Em 2008 um incêndio que durou mais de quatro horas destruiu o Teatro Cultura Artística em São Paulo ${ }^{10}$. O afresco de Di Cavalcanti, de 48 x 8 metros, localizado na fachada, é um dos poucos pontos da estrutura original que pode ser restaurado ${ }^{16}$.

Em 15 de maio de 2010, um incêndio no Instituto Butantan, em São Paulo, atingiu a maior e a mais antiga coleção do mundo em seu gênero, a coleção herpetológica "Alphonse Richard Hoge", criada em 1896 por Vital Brazil. A coleção possuía cerca de 77.000 serpentes cadastradas e cerca de 5.000 que ainda não haviam sido registradas. Além da maior coleção de ofídios da região tropical, a parte do galpão que foi dominada pelas chamas guardava também milhares de exemplares de aranhas ${ }^{10,17}$. 
Em 10 de novembro de 2012, um incêndio atingiu o Seminário Episcopal da Luz, construído entre 1853 e 1856, localizado na Rua São Caetano, Centro de São Paulo. Prédio histórico com fachada preservada, mas em seu interior funcionavam lojas de artigos para noivas ${ }^{10,18}$.

Em 23 de dezembro de 2012, um incêndio atingiu uma área do terceiro andar da Biblioteca Pública Luiz Bessa, na Praça da Liberdade, em Belo Horizonte. As chamas foram controladas pelo Corpo de Bombeiros e não danificaram o acervo da biblioteca. Somente móveis, material de escritório e alguns computadores da área administrativa foram destruídos ${ }^{19}$.

Em 22 de janeiro de 2013, um incêndio atingiu o Museu de Ciências Naturais da Pontifícia Universidade Católica de Minas Gerais (PUC-Minas), localizado no bairro Coração Eucarístico, em Belo Horizonte. De acordo com a universidade, somente as coleções que ficavam no segundo andar foram atingidas ${ }^{20}$.

Em 26 de janeiro de 2013, o fogo destruiu uma casa de alvenaria integrante do complexo do Centro Municipal de Cultura de Gramado, na Serra Gaúcha, que abrigaria um museu com o acervo histórico do municípioº ${ }^{21}$.

Em 8 de fevereiro de 2013, no Rio de Janeiro, bombeiros do quartel de Vila Isabel combateram um princípio de incêndio que atingiu o antigo Museu do Índio, no Maracanã ${ }^{22}$.

Em 3 de março de 2013, chamas destruíram mais da metade de um dos prédios da biblioteca do Instituto de Estudos da Linguagem (IEL) da Unicamp, em Campinas. As áreas atingidas pelo incêndio foram o local para atendimento ao público e o de catalogação dos livros e, por esta razão, alguns foram queimados. A área destinada ao acervo, com 1.881 metros quadrados, não foi afetada e não houve feridos ${ }^{23}$.

Em 13 de maio de 2013, um incêndio atingiu o prédio da biblioteca da Faculdade de Direito da Universidade Federal do Amazonas (Ufam), localizada na Avenida Rodrigo Otávio, Zona Centro-Sul de Manaus. Cerca de 300 livros e materiais de pesquisa foram destruídos. A suspeita é a de que o fogo tenha sido iniciado no aparelho de ar-condicionado da sala ${ }^{24}$.

Em novembro de 2013, um incêndio de grandes proporções destruiu o interior do auditório Simon Bolivar, prédio projetado por Oscar Niemeyer, que faz parte do Memorial da América Latina, localizado na cidade de São Paulo. Nessa ocasião 16 pessoas ficaram feridas. A prefeitura não renovava seu alvará de funcionamento para o local desde $1993^{10}$.

Em 4 de fevereiro de 2014, o fogo atingiu o Liceu de Artes e Ofícios de São Paulo, fundado em 1873, localizado na Luz, região central da cidade. Nessa ocasião foram queimados quadros, esculturas, móveis antigos e réplicas de gesso. Assim como o Memorial da América Latina, o Liceu também não tinha alvará de funcionamento há 20 anos ${ }^{10,12}$. Especial carinho tenho por essa instituição, referência na cidade como escola de ensino técnico profissionalizante e de formação geral, na qual meu pai, nascido em Estrasburgo, França, em 1932, fez seu curso de Contabilidade.

Em 21 de dezembro de 2015, foi a vez do Museu da Língua Portuguesa, em São Paulo, após nove anos de sua inauguração, arder em chamas em um incêndio de grandes proporções, que acabou causando a morte de um bombeiro e a destruição do local ${ }^{10}$. Era considerado um dos museus mais visitados do Brasil e da América do $\mathrm{Sul}^{13,25}$.

O que há de comum em todos esses eventos é o descaso das autoridades responsáveis pelo financiamento que garanta a guarda, a preservação, o acesso e a segurança dos acervos. Acredita-se que muitas destas não tenham a menor ideia da importância e relevância para o país do patrimônio histórico e cultural que está sob a responsabilidade do Estado. É difícil valorizar o que não se conhece. Fábricas podem ser reconstruídas, mas patrimônio histórico não, nunca.

Comum também é o investimento de grandes somas após os sinistros. O que não havia para a preservação, conservação e segurança aparece de forma mágica para conter a opinião pública. Nessa reconstrução, muitas vezes se apela para a tecnologia como uma forma natural para substituir os originais perdidos.

É triste perceber que há pessoas que acreditam que uma cópia em 3D pode substituir uma peça original. Há de se enxergar além do material. E, para isso, é necessário um mínimo de conhecimento e respeito pela memória, não só do país, como da humanidade. 


\section{Referências}

1. Redação Época. Após incêndio, parte do prédio da UFR] desaba [Internet]. Época. 2011 [citado 2018 set. 16]. Disponível em: http://revistaepoca.globo.com/Revista/Epoca/0 „EMI221758-15228,00-APOS+IN CENDIO+PARTE+DO+PREDIO+DA+UFRJ+DESABA.html

2. Paula D, Barreto D. Incêndio atinge prédio da Faculdade de Letras da UFRJ [Internet]. O Globo. 2012 [citado 2018 set. 16]. Disponível em: https://oglobo.globo.com/rio/incendio-atinge-predio-da-faculdadede-letras-da-ufrj-6042436

3. G1 Rio. Curto-circuito provoca incêndio em laboratório de microbiologia da UFR] [Internet]. G1. 2017 [citado 2018 set. 16]. Disponível em: http://g1.globo.com/rio-de-janeiro/noticia/2014/12/curto-circuitoprovoca-incendio-em-labortatorio-de-microbiologia-da-ufrj.html

4. Assessoria de imprensa do Gabinete do Reitor. Nota sobre incêndio no $8^{\circ}$ andar do prédio da Reitoria [Internet]. 2016 [citado 2018 set. 16]. Disponível em: https://ufrj.br/noticia/2016/10/04/nota-sobreincendio-no-8o-andar-do-predio-da-reitoria

5. Estadão Conteúdo. Alojamento da UFR] pega fogo e estudantes ficam feridos [Internet]. Exame. 2017 [citado 2018 set. 16]. Disponível em: https://exame.abril.com.br/brasil/alojamento-da-ufrj-pega-fogo-eestudantes-ficam-feridos/

6. Princípio de incêndio atinge nono andar do Hospital do Fundão [Internet]. Extra. 2018 [citado 2018 set. 16]. Disponível em: https://extra.globo.com/noticias/rio/principio-de-incendio-atinge-nono-andar-dohospital-do-fundao-22708625.html

7. Assessoria de imprensa do Gabinete do Reitor. Nota oficial [Internet]. 2018 [citado 2018 set. 16]. Disponível em: https://ufrj.br/noticia/2018/05/23/nota-oficial

8. IG São Paulo. Aluna grávida e dois técnicos ficam feridos em explosão de laboratório da UFR] [Internet]. Último Segundo. 2018 [citado 2018 set. 16]. Disponível em: https://ultimosegundo.ig.com.br/ brasil/2018-08-15/explosao-laboratorio-ufrj.html

9. Neves MS. Lugares de Memória da Medicina no Brasil [Internet]. [citado 2018 set. 16]. Disponível em: http://www.historiaecultura.pro.br/cienciaepreconceito/lugaresdememoria/faculdadedemedicinadabahia.htm

10. Leite E. Fogo já destruiu vários acervos no Brasil [Internet]. Estadão. 2018 [citado 2018 set. 16]. Disponível em: https://acervo.estadao.com.br/noticias/acervo,fogo-ja-destruiu-varios-acervos-nobrasil,70002486333,0.htm

11. G1 São Paulo. Incêndio atinge área da Cinemateca Brasileira, na Zona Sul de São Paulo [Internet]. G1. 2016 [citado 2018 set. 16]. Disponível em: http://g1.globo.com/sao-paulo/noticia/2016/02/incendioatinge-area-da-cinemateca-brasileira.html

12. Em 10 anos, fogo dizima ao menos 8 prédios com tesouros culturais e científicos do país [Internet]. Folha de S. Paulo. 2018 [citado 2018 set. 17]. Disponível em: https://www1.folha.uol.com.br/ cotidiano/2018/09/em-10-anos-fogo-dizima-ao-menos-8-predios-com-tesouros-culturais-e-cientificos-dopais.shtml

13. Buarque SM. Quando a história vira cinza. Memória Ativa. 2016 [citado 2018 set. 18]:4-11.Disponível em: http://arquivopublico.pe.gov.br/arquivos/Revista_MemoriaAtiva2 email.pdf

14. Artes visuais: construções sensíveis [Internet]. 2018 [citado 2018 set. 17]. Disponível em: http:// culturabancodobrasil.com.br/portal/construcoes-sensiveis-a-experiencia-geometrica-latino-americana-nacolecao-ella-fontanais-cisneros/

15. Museu Nacional já sofria com problemas de infraestrutura [Internet]. Extra. 2018 [citado 2018 set. 18], Disponível: https://extra.globo.com/noticias/rio/museu-nacional-ja-sofria-com-problemas-deinfraestrutura-23032870.html

16. Agência Estado. Afresco escapa de incêndio no Teatro Cultura Artística [Internet]. Estadão. 2008 [citado 2018 set. 18]. Disponível em: https://www.estadao.com.br/noticias/geral,afresco-escapa-de-incendiono-teatro-cultura-artistica, 226084

17. Vital Brazil E. A Casa de Vital Brazil de luto [Internet]. Digestivo Cultural. 2010 [citado 2018 set. 17]. Disponível em: https://www.digestivocultural.com/blog/post.asp?codigo=2662\&titulo=A Casa de Vital Brazil de luto

18. Prédio destruído por incêndio em São Paulo abrigava seminário do século 19 que passava por restauro [Internet]. UOL Notícias. 2012 [citado 2018 set. 17]. Disponível em: https://noticias.uol.com.br/ 
cotidiano/ultimas-noticias/2012/11/10/local-destruido-por-incendio-em-sao-paulo-abrigava-seminariodo-seculo-19-que-aguardava-restauro.htm

19. Incêndio atinge prédio da Biblioteca Pública Luiz Bessa, em Belo Horizonte [Internet]. 2012 [citado 2018 set. 16]. Disponível em: https://blogsci.com.br/2013/01/07/incendio-atinge-predio-da-biblioteca-publicaluiz-bessa-em-belo-horizonte/

20. Incêndio atinge museu de universidade em Belo Horizonte [Internet]. 2013 [citado 2018 set. 16]. Disponível em: https://blogsci.com.br/2013/01/23/incendio-atinge-museu-de-universidade-em-belohorizonte/

21. Incêndio destrói construção histórica em Gramado [Internet]. 2013 [citado 2018 set. 16]. Disponível em: https://blogsci.com.br/2013/01/28/incendio-destroi-construcao-historica-em-gramado/

22. Princípio de incêndio afeta o antigo Museu do Índio na Zona Norte do Rio [Internet]. 2013 [citado 2018 set. 16]. Disponível em: https://blogsci.com.br/2013/02/13/principio-de-incendio-afeta-o-antigo-museudo-indio-na-zona-norte-do-rio/

23. Incêndio atinge prédio da biblioteca do Instituto de Letras da Unicamp [Internet]. 2013 [citado 2018 set. 16]. Disponível em: https://blogsci.com.br/2013/03/04/incendio-atinge-biblioteca-da-unicamp-areaqueimada-e-de-470-m\%C2\%B2/

24. Incêndio atinge prédio de biblioteca de faculdade da Ufam, em Manaus [Internet]. 2013 [citado 2018 set. 16]. Disponível em: https://blogsci.com.br/2013/05/14/incendio-atinge-predio-de-biblioteca-defaculdade-da-ufam-em-manaus/

25. G1 São Paulo. Incêndio atinge Museu da Língua Portuguesa em São Paulo [Internet]. G1. 2015 [citado 2018 set. 16]. Disponível em: http://g1.globo.com/sao-paulo/noticia/2015/12/incendio-atinge-museuda-lingua-portuguesa-em-sp-dizem-bombeiros.html 